\title{
Nanolevel Finishing for Veneered Products
}

\author{
Edgars Kirilovs, Laura Krūklīte, Silvija Kukle, Zane Zelča \\ Riga Technical University \\ Address: Azenes street 18, Riga, LV-1048, Latvia.
}

\begin{abstract}
Wood veneer is mainly used for interior decoration applications in many different segments. It's ideal for residential projects, hotel projects, offices giving to the any interior a unique look and feel. In addition, veneer is also processed to create a variety of products such as veneer parquet, flexible veneer sheets, wood veneer boards, wood veneer wallpaper, etc. From the other side, veneered surfaces will always to a greater or lesser degree change color, particular upon exposure to natural and artificial light. The degree of color change will depend on such factors as the species chosen, the coating type used and intensity and period of the exposure to light. In addition, conventional finishes have a tendency to yellow with age which can have quite dramatic effects on the original color of the selected timber. To minimize these effects new finishes have to be developed. In the paper new, invisible nanolevel coating for veneer finish based on the sol-gel process is offered. It is known that the sol-gel technique is an established industrial process for the generation of colloidal nanoparticles from liquid phase, which has been further developed in last years for the production of advanced coatings. It is well adapted for oxide nanoparticles and composites synthesis. The main advantages of sol-gel techniques are comparable low processing temperatures offering unique opportunities for access to organic and inorganic materials. The sol synthesis and application technology as well protective properties of coating will be discussed.
\end{abstract}

Keywords: Wood veneer, advanced coatings, sol-gel technique, organic materials.

\section{INTRODUCTION}

Birch wood microscopy

Veneer is the finest use of timber, because it is real timber.

The benefits of its use are:

- the natural variations of timber means each project is individual as choice from the vaste array of species, colors and textures are available; even from the same specie veneers differ in grain, color, texture and markings;

- they are pleasant and friendly to the touch;

- adds prestige and style to the furniture and joinery;

- veneer can be molded to fit any shape and adhered to a different substrates to give all the versatility of solid timber; various types of substrates can be used for the production of veneered panels and furniture, such as solid timber, particle boards, medium density fiber boards, plywood, block boards, and hardboards;

- veneer is highly efficient use of timber as one cubic meter of $\log$ could produce around 1000 square meters of veneer;

- veneer is sustainable use of forest resources. [1]

The main sources of veneers are hardwoods with the more complicated anatomy compared to softwoods and as consequence more complicated wood structure.

Veneer quality is a factor in construction and industrial plywood based on visually observable characteristics. Knots, decay, splits, insect holes, surface roughness, number of surface repairs, and other defects are considered. Veneer species and characteristics are also a major factor in categorization of hardwood and decorative plywood.

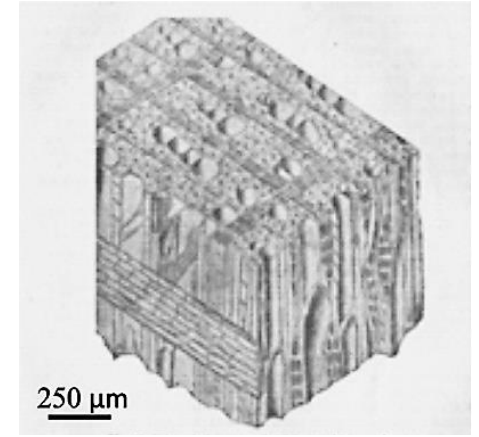

Figure 1. Anatomical features of birch [2]

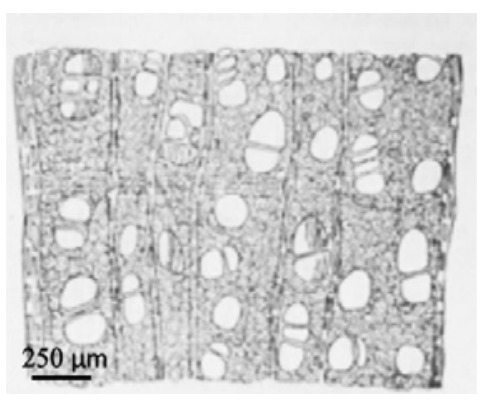

Figure 2. Birch cross section [2] 
However, when observing the microstructure of a hardwood sample in practice it is normally only easy to see the vessels, fibres and parenchyma cells, since the tracheids are very few in number.

The hardwood axial system is composed of vessel elements in various sizes and arrangements, and of axial parenchyma in various patterns and abundance (Fig.1). As in softwoods, rays comprise the radial system and are composed of ray parenchyma cells, but hardwoods show greater variety in cell sizes and shapes. Vessel elements are stacked one on top of the other to form vessels. On the transverse section, vessels appear as large openings and are often referred to as pores (Fig. 1 and 2). Vessel diameters may be small $(<30 \mu \mathrm{m})$ or quite large $(>300 \mu \mathrm{m})$, but typically range from 50 to $200 \mu \mathrm{m}$. They are much shorter than tracheid's and range from 100 to $1,200 \mu \mathrm{m}$.[2]

If all the vessels are the same size and more or less scattered throughout the growth ring, the wood is diffuse- porous. If the early wood vessels are much larger than the latewood vessels, the wood is ringporous. Diffuse-porous species woods maple and birch have two main types of growth rings and one intermediate form. In diffuse-porous woods, vessels either do not markedly differ in size and distribution from the earlywood to the latewood, or the change in size and distribution is gradual and no clear distinction between earlywood and latewood can be found (Fig. $2)$. Vessels can also be arranged in a tangential or oblique arrangement in a radial arrangement, in clusters, or in many combinations of these types. In addition, individual vessels may occur alone (solitary arrangement) or in pairs (Fig. 2), or radial multiples of up to five or more vessels in a row. Where vessel elements come in contact with each other tangentially, intervessel or intervascular bordered pits ranging in size from 2 to $>16 \mu \mathrm{m}$ in height are formed (Fig.3).

Hardwoods have a wide variety of axial parenchyma patterns. Paratracheal parenchyma is associated with the vessels, and further divided into vasicentric (surrounding the vessels), aliform (surrounding the vessel and with wing-like extensions), and confluent (several connecting patches of paratracheal parenchyma sometimes forming a band).

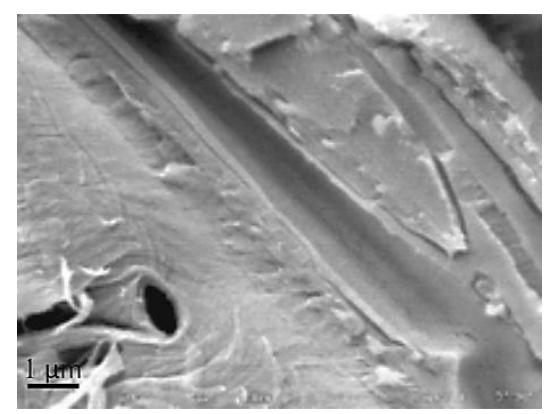

Figure 3. Exposed channel of hardwood showing pit [3]

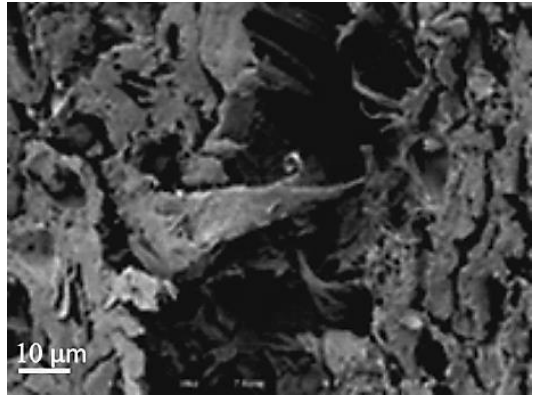

Figure 4. Hardwood microstructure [3]

Apotracheal parenchyma is not associated with the vessels and is divided into diffuse (scattered), diffusein-aggregate short bands and banded, whether at the beginning or end of the growth ring or within a growth ring. Each specie has a particular pattern of axial parenchyma, which is more or less consistent from specimen to specimen, and these cell patterns are important in wood identification. The rays in hardwoods are structurally more diverse than those found in softwoods. Most species have rays that are more than one cell wide. In oak and hard maple, the rays are two-sized, uniseriate and more than eight cells wide. Such hardwood anatomy specifics and differences between species lead to a very complicated and uneven veneer surface microstructure (Fig. 4). Small holes are typically created when the wood cells shrink during the drying process at the mill. Cracks can also occur when a veneer loses too much moisture (or loses moisture too quickly). When this happens, internal stresses become so strong that the wood cells shrink, lose elasticity, and then separate from each other. These types of splits are more challenging to repair. The success rate for repairing this type of crack depends on several factors. It is difficult to select the highest quality logs, because many internal defects such as gum veins, rot and insect damages are difficult to detect from the log outside. Probably the most critical aspect of preparation for finishing is the moisture content of veneered products. Equilibrium moisture content of veneer are approximately 10 to $12 \%$. High moisture content is difficult to detect visually so prevention is a key.

\section{Birch wood veneer surface modification}

One of the different new approaches and possibly one of the most promising for surface modification of materials is the sol-gel technology. Probably this technology offering possibilities to tailor surface properties to a certain extent and to combine different functionalities in a single material was one of the most important developments in material sciences during the last decades. At the same time the application of sols can be carried out with the techniques commonly used in finishing processes such as immersion or sprinkling following by thermal processing. 
Colloid solutions of nano sized oxides particles in aqueous or organic solvents or in their mixtures (nanosols) today become more and more popular. Due to the high surface area of the small particles the nanosols are metastable and during coating process the particles will aggregate as well as condense, initiated by evaporation of solvent in result of thermal treatment. Process result in dense three-dimensional networks leading in coatings which exhibit new functions.[4]

In comparison with many other materials such as ceramics or metals, wood products possess low thermal resistance. The conditions for the treatment and the sol composition have to be adapted to the particular demands of material. As chemical structure of such natural fibres as flax and hemp are close to the chemical structure of hardwoods, the sol synthesized for cotton and lignocellulosic fiber textiles surface modification are used. Obtained by this sol modified textile surfaces had presented excellent protection from ultraviolet radiation, antimicrobial activity and water repellency. All mentioned properties are important to improve protection of veneered surfaces in outdoor and indoor applications.[5]

Some stains, notably dye stains can fade if subjected to long term ultra violet light; if wooden surface is not protected, destruction of lignin could be caused by UV radiation.

Under direct sunlight fading, bleaching or color changes of veneered surfaces may occur. Excessive hot sunshine may dry the veneer surface more quickly than substrate thereby causing appearance of small surface checks parallel to the grain and possible damage of the coating. Treated with the sol surface will become more protected due to the restricted water vapor transmittance.

It is well known that all chemical substances and alcohols should be removed immediately from all veneered surfaces to avoid their damages. Water repellency property doesn't allow liquid to penetrate into surface and make it easy-to-clean.

Antimicrobial properties are necessary in a wide range of uses such as furniture of public and hospital premises, kitchen, dining room and bathroom furniture, outdoor constructions and furniture etc.

In Latvia work with implementation of modern waste management system was started in middle nineties of the 20th century. Up to date the system is sufficiently well developed, especially in landfill field. Until year 2012 in Latvia it is planned to be build 1012 municipal solid waste sanitary landfills.

\section{MATERIALS AND METHODS}

\section{Sol-gel method}

The veneer samples were modified in the prepared sols with and without Zinc acetate dehydrate, acetone pretreatment and $\mathrm{SiO} 2$. Sols were synthesized using silica alkooxide tetraetylortosilicate, ethanol and water added to perform the hydrolysis and condensation, and hydrofluoric acid used as a catalyst. Zinc acetate dehydrate was used as the modifier of the sol-gel system. After the treatments, the samples were dried in an oven with the following thermal post-treatment, low temperature thermal treatment the drying and thermal post-treatment were combined [5].

Veneer is treated with acetic anhydride $1,5 \mathrm{~h} 24 \mathrm{C}$ $80 \%$ aqueous solution, then pressed for $2 \mathrm{~min}$ in $50{ }^{\circ} \mathrm{C}$ and loaded till is completely dry not to damage.

\section{Adhesion theory and wetting parameters}

Several adhesion mechanisms or theories have been proposed and applied in the adhesion science and technology field [6]. This work involves the wetting (or adsorption) theory, which by far is the most applied concept for evaluation of theoretical secondary (non-covalent) bonding, for example hydrogen bonding, i.e. interfacial forces relevant mainly for adhesion and gluing technology. Wetting phenomena can be defined as "macroscopic manifestations of molecular interactions between liquids and solids in direct contact at the interface between them" [7]. Surface free energy, contact angles and work of adhesion are some parameters that define the wettability of materials.

Four basic types of birch wood veneer specimens with dimensions of $100 \times 100 \times 0.6 \mathrm{~mm}$ and $15 \times 15 \times 0.6$ $\mathrm{mm}$ were prepared: reference samples of unmodified wood, and four types of modified wood samples, i.e. 1) modified with silica sol and two different regimes of thermal post-treatment $120{ }^{\circ} \mathrm{C}$ and $140{ }^{\circ} \mathrm{C}, 2$ ) modified with $\mathrm{Zn}$ diacetate sol and two different regimes of thermal post-treatment $120{ }^{\circ} \mathrm{C}$ and $140{ }^{\circ} \mathrm{C}$.

Figure 5 illustrates an equilibrium state of a drop of liquid surrounded by a gas at a solid surface. This is the fundamental basis for the Young's equation (1) and is expressed as:

$$
\mathrm{\gamma}_{\mathrm{LG}} \cos \theta=\mathrm{\gamma}_{\mathrm{SG}}-\mathrm{\gamma}_{\mathrm{SL}}
$$

where $\theta$ is the liquid-solid-air contact angle, $\mathrm{V}_{\mathrm{LG}}$ and $\mathrm{V}_{\mathrm{SG}}$ are the surface free energies of the liquid (L) and the solid (S), respectively, exposed to a gas (G), and $\mathrm{V}_{\mathrm{SL}}$ is the solid-liquid interfacial free energy.[5]

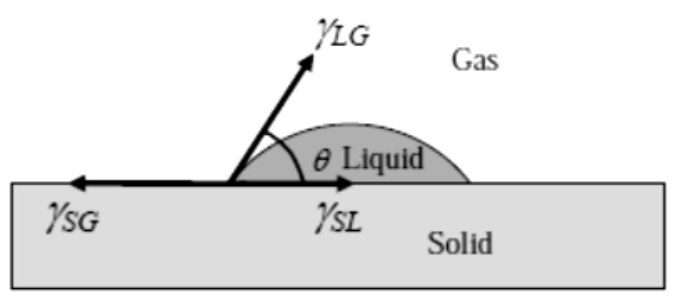

Figure 5. Equilibrium state of a drop of liquid surrounded by a gas on a solid surface. 


\section{Atomic Force Microscope}

Atomic Force Microscope (AFM) is relatively new technique used for the surface characterization. In AFM, one scans the sample surface with a sharp probe or tip, situated at the apex of a flexible cantilever that is often a diving board or V-shaped, usually made of silicon. The AFM utilizes a piezoelectric scanner that moves the sample in 3 dimensions by a subnanometer amount when a voltage is applied. To form an image, the tip is brought close to the sample and rasterscanned over the surface, causing the cantilever to be deflected due to probe-sample interactions. A line-byline image of the sample is formed as a result of this deflection, which is itself detected using laser light reflected off the back surface of the cantilever onto a position-sensitive photodiode detector.[8]

AFM was applied to investigate the morphology of veneer. Height was scanned using silicone probe. Cantilever was $125 \mu \mathrm{m}$ long and height at 15-20 $\mu \mathrm{m}$. Test operated in Tapping mode, image size 50x50 $\mu \mathrm{m}$ with Scan Rate 0,1 Hz. Probe nominal tip radius, Spring constants and free resonance frequencies were $3,75 \mu \mathrm{m}, 40 \mathrm{~N} / \mathrm{m}$ and $300 \mathrm{kHz}$. The reference voltage was set to $2.6+-0,2 \mathrm{~V}$, a level that provided clear images.

\section{RESULTS AND DISCUSSION}

A popular chemical treatment method esterification usually involves reactions with organic acids or anhydrides. In acetylation process hydroxyl groups of hemicelluloses and lignin react with acetic anhydride, forming esters (Fig.6).<smiles>CCCC(CC)NCC(C)OC(C)OC(C)O</smiles>

Figure 6. Esterification process

The obtained hydrophobic nature of the fibres is more compatible with non-polar polymers used as matrix. It is reported that treatment with acetic anhydride improve the adhesion and compatibility between the two phases of composite. In addition to this, better performance is acquired such as lower moisture absorption, higher wettability and improved mechanical properties and dimensional stability. Also, these chemical treatments improve the thermal and thermo-oxidative stability of the composite materials, by increasing their oxidation temperature (Fig. 7; 8).

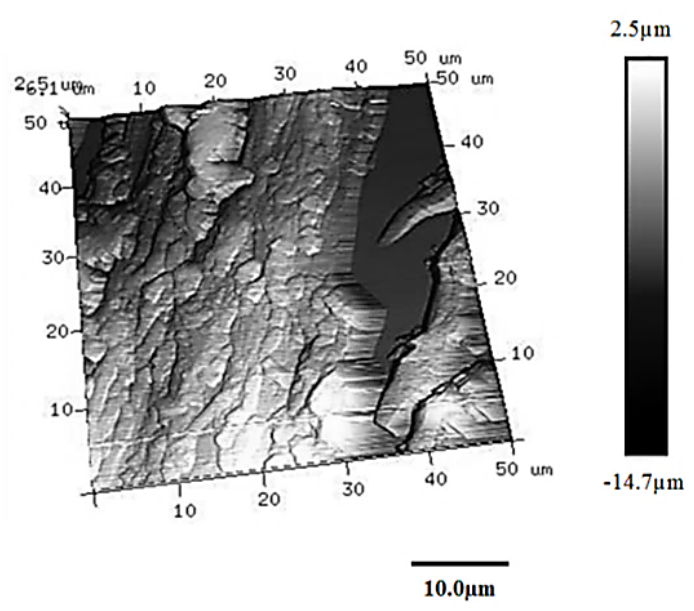

Figure 7. Sanded veneer processed with acetic anhydride, 3D surface

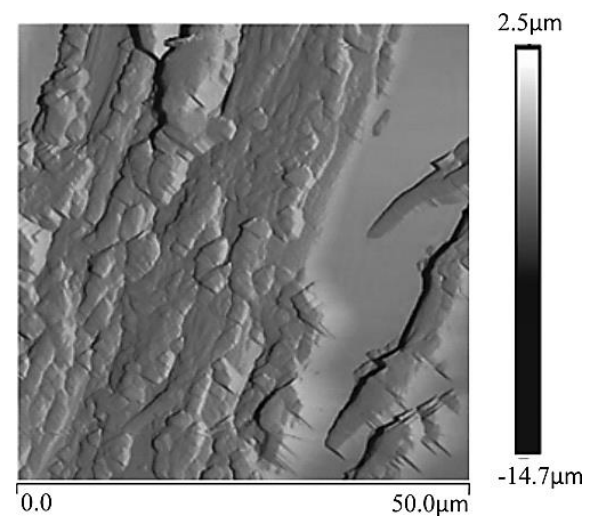

Figure 8 . Sanded veneer processed with acetic anhydride, 2D surface

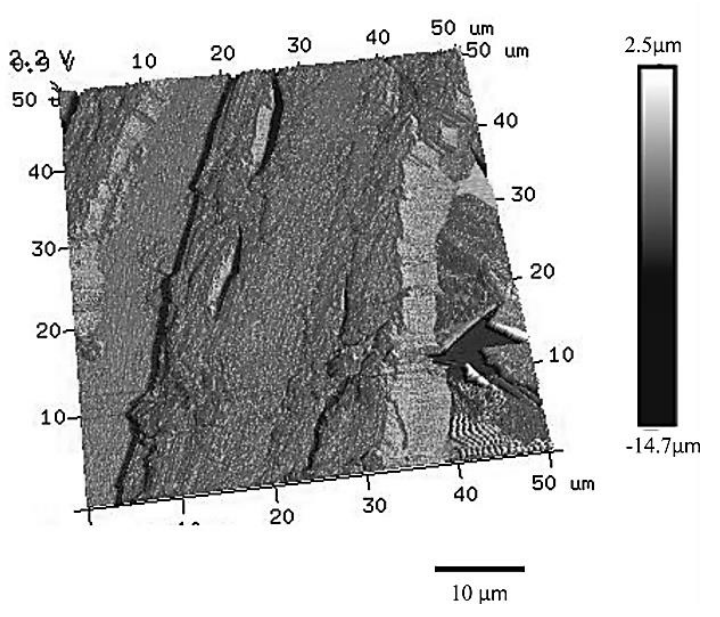

Figure 9. Sanded veneer processed with $\mathrm{SiO}_{2}, 3 \mathrm{D}$ surface

Figure 9 shows the sliced birch veneer sample that is treated with $\mathrm{SiO}_{2}$ solution using the sol-gel method. Before soaking the sample in $\mathrm{SiO}_{2}$ liquid, it was twice sanded. Among the sanding there was done wetting and drying. Although the material was wetted between the sanding, after soaking it in $\mathrm{SiO}_{2}$, there was a 
material irregularity of the surface, which can be explained by fibre lift up. This is also reflected in Figure 9.

Figure 10 shows birch veneer sample prior to processing, and Figure 11 shows a sample after treatment with $\mathrm{Zn}$ diacetate. After treatment of the sample there is observed terrain flattening that could be explained by the fact that the slightest relief wells are completed with $\mathrm{Zn}$ diacetate nano particles. $\mathrm{Zn}$ has effected the material so coloring it darker. The coating also reduces the presence of water absorption, and the drop is formed on the surface.

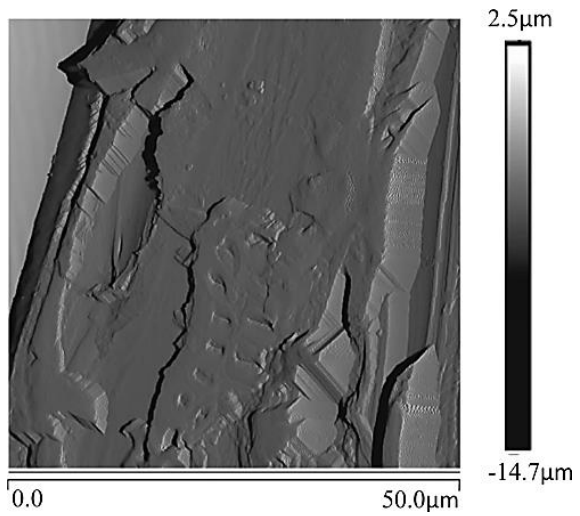

Figure 10. Unmodified veneer sample

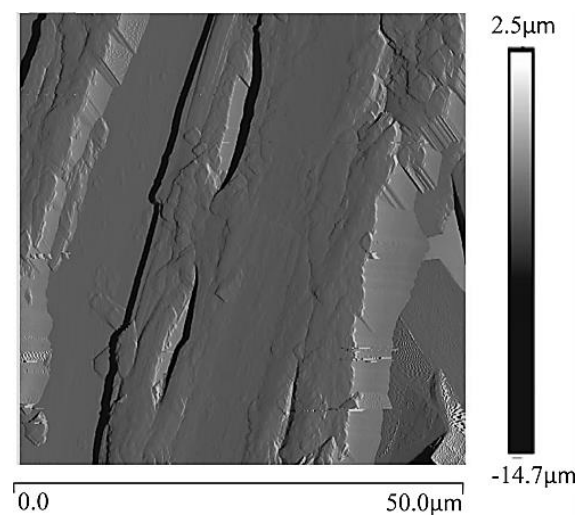

Figure 11. Modified sample by $\mathrm{Zn}$ acetate sol

Figure 12 shows that on the untreated surface drop smoothest over the surface, while Figure 13 shows that due to the $\mathrm{Zn}$ treatment diacetate drop retains its shape. There is formed a surface coating that reduces water absorption ability of the material. Further research is needed to determine the surface protective sustainability.

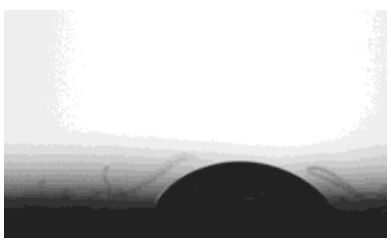

Figure 12. Unmodified veneer sample

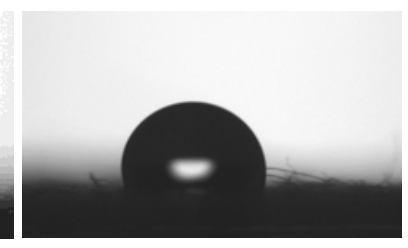

Figure 13. Modified veneer sample by $\mathrm{Zn}$ acetate sol

\section{CONCLUSION}

Regardless in which sol-gel liquid the veneer was soaked, the treatment improved resistance to water uptake. The sol-gel process formed a thin film of acetic anhydride, $\mathrm{SiO}_{2}$ and $\mathrm{Zn}$ diacetate. Sample processing using acetic anhydride, requires two to four hours to achieve a sample size stability. But using silicon and zinc liquid, it requires 10 to 15 minutes. Further research is needed to determine the surface protective sustainability against various external influences and in premises with high moisture content.

\section{REFERENCES}

[1] MacGregor J. Prepearing and applying decorative wood veneers and inlays to substrates, Forest and wood products research and development corporation, 2004, pp 80.

[2] Forest Products Laboratory, Wood Handbook -- Wood as an Engineering Material [author's book] Michael C. Characteristics and Availability of Commercially

Important Woods. Madison: Department of Agriculture, Forest Service, Forest Products Laboratory, 2010.

[3] Shmulsky R., Jones D. Forest Products and Wood Science. Wiley-Blackwell. 2011, pp 496.

[4] Sumo Sakka E. Handbook of Sol-Gel Science and Technology: Processing, Characterization and Applications, Springer, 2004, pp 1980

[5] Vihodceva S. Extension of the Range of Textile Modified at Nano-Level. Latvia: Institute of design technology, Department of material technology and design, 2014. Doctoral Thesis.

[6] Schultz, J. and Nardin M., Theories and mechanisms of adhesion. In: Adhesion Promotion Techniques, Technological Applications. Eds. Mittal, K.L., Pizzi, A. Marcel Dekker Inc. 1999. pp. 1-26., ISBN 9780824702397

[7] Berg, J. C. Role of Acid-Base Interactions in Wetting and Related Phenomena. Wettability. Ed. Berg, J.C. Marcel Dekker, 1993. New York. pp. 75-148, ISBN

[8] Leite F.L., Mattoso L. H. The Atomic Force Spectroscopy as a Tool to Investigate Surface Forces: Basic Principles and Applications. Formatex.2007. pp 747-757. 